iron formulæ," and assumes that he presupposes a few dogmas along with homeopaths and osteopaths; but this may pass.

The point is that medicine is not an abstract science, but the application of all sciences to the laws of the body and mind. The successful physician does his investigating in the hospital wards. He takes side courses in sociologic problems, in heredity, in temperament, and in the art of adaptation. He is, in the finished product, a detective, a judge, a confessor, a teacher, a comforter as well as a healer of sick bodies. So the professors of anatomy and physiology, and materia medica, must remember that their students are not going to be anatomists, or physiologists, or pharmacologists, but physicians; and that these studies are but the tools with which they are to work. They want to get them, and keep them sharp; that is all.

S. E. JeLLIfFe, M.D.

\section{Kirke's Handbook of Physiology.}

50 Altsemarle. St., London, W., Feb. 8, 1900.

To the Editor: In $1896 \mathrm{I}$ had to call attention to the fact that Messrs. Wm. Wood \& Co. of New York were publishing an unauthorized edition of Kirke's well-known Manual of Physiology. I have recently obtained a copy of the 15th edition of their work, bearing date 1899 , and having on the title page the names of Mr. Morrant Baker and Dr. Vincent Harris as editors.

The facts are as follows: Mr. Morrant Baker-who is now dead-and Dr. Vincent Harris gave up the editorship of the genuine work four years ago, and even before that time Messrs. Wood \& Co. never had their permission to use their work or their names. Since 1895-6 Professor W. D. Halliburton has been sole editor of the Handbook: he has almost re-written the work from beginning to end, although Kirke's name has been retained.

One of the special features of our book is a series of colored illustrations of blood-corpuscles, blood-crystals, etc. These, together with many alterations and improvements, both in cuts and text, which have been introduced by Professor Halliburton, have been adopted by Messrs. Wood \& Co. without any acknowledgement of the source whence they were derived, and in the teeth of a protest by Professor Halliburton and myselfwho am the proprietor of the book.

Not only have Messrs. Wood \& Co. "conveyed" a large amount of Professor Halliburton's original work, but they have also issued their book. under the names of Mr. Morrant Baker and Dr. Vincent Harris, who have nothing to do with it.

I think it is but right that I should again call the attention of the American medical profession to this glaring and persistent case of literary piracy, for the present United States law gives me no other redress.

The only authorized and complete edition of Kirkes' Physiology sold in America is that published by Messrs. P. Blakiston's Son \& Co., of Philadelphia, in conjunction with my firm. I am, Sir, Yours faithfully, John Murray.

\section{Typhoid Peculiarities Following Sunstroke.}

\section{Point Arena, Cal., Feb. 9, 1900.}

To the Editor: During a general country practice of over twenty-three years, I have treated about two hundred and fifty patients with typhoid fever, and in three, all men in the prime of life, a decided peculiarity has been shown in the duration and character of the delirium. The usual symptoms and general characteristics in all, except the three to which I allude, were present, and there was no marked deviation from the symptoms we would expect to see in that disease. But in the three the delirium was extraordinarily prolonged, neither of them being free from that condition for a period less than three weeks, and two of them for about four weeks. A peculiar type of the delirium was that the patients were quite rational so long as they were being talked to, but would relapse into hallucinations and various manifestations of brain derangement when left alone. They would recognize faces of friends and old-time acquaintances, and voices and other sounds, as well apparently as if they were not sick. I met the first of the three in 1885, during an epidemic of fever. The oddity of the case attracted my attention especially, and I made careful inquiry into the past life of my patient. The only thing I could learn was that he had suffered a severe attack of sunstroke some years before, from which he did not fully recover for two months. On meeting the other two, one in 1891, and the other last November, I noticed the same peculiar symptoms, and on inquiry found that they too had suffered severely from sun. stroke.

I desire to know whether insolation leaves any lesion of the brain that renders it susceptible to the typhoid toxin causing that peculiar type of delirium. It seems to me the subject is of sufficient interest to engage the thoughts of our neurologists, and justify investigation. Gko. J. Brown, M.D.

\section{Students and Medical Practice.}

CaMden, S. O., Feb. 14, 1900.

To the Editor, - In THE Joninat of February 10, you edi torially mention that "The medical students of South Carolina have succeeded in obtaining legislation exempting them from the state examinations, . . . The bill to exempt all graduates from the only medical college in the state did pass the house, but the senate was wiser and more conservative, and killed it. I think that the young gentlemen who pushed this matter were lacking in forethought and discretion. The object of the State Board's examination is to keep down quackery, and if one bar is taken down, there will be danger to the entire fence. One of the arguments against standing the examination was the necesary expense of the trip to the capitol eity, where the Board meets, a matter of say $\$ 25$. The time will come when these young gentlemen will be pleased that they went to this expense and trouble. They will some day appreciate the value of a board which must pass upon all applicants to practice medicine in the state.

There is no doubt that they who get their diplomas from the Medical College of the State of South Carolina will successfully pass this examination, but strangers to them might think that their zeal in the matter of legislation against the examinations means a lack of confidence in themselves or in the college. I understand that the faculty is as a body opposed this bill; so it seems that they have plenty of confidence, and justly so, in the high standard of the Medical College of the State of South Carolina. JNo. W. Conbetr, M.D.

\section{Books Received.}

Acknowledgement of all books received will be made in this column, and this will be deemed by us a full equivalent to those sending them. A selection from these volumes will be made for

The Aristophilon. A Nemesis of Faith. By Frank D. Bullard, A.M., M.D., I2mo. Cloth. Pp. 110 . Price $\$ 1.50$. Chicago. R. R. Donnelley \& Sons Co. 1899.

The Retrospect of Medicive. A Half-yearly Journal, Containing a Retrospective View of Every Discovery and Practical Improvement in the Medical Sciences. Edited by James Braithwaite, M.D., and others. Vol. 120. July-December, 1899. 8vo. Cloth. Pp. 442. Price 6/6. London: Simpkins, Marshall, Hamilton, Kent \& Co., Itd. 1900.

A Text-Book of Materia Medica, Therapeutrcs and Pharmacology. By George Frank Butler, Ph.G., M.D., Professor of Materia Medica and Clinical Medicine in the College of Physicians and Surgeons. Third Edition. 'Thoroughly Revised. Svo. Cloth. Pp. 874. Price \$4.00. Philadelphia: W. B. Saunders. I899. W. T. Keener \& Co., Chicago Agents.

A Treatise on the Principres and Practice of Grnecol. ogY. By E. C. Dudley, A.M., M.D., Professor of Gynecology in the Northwestern University Medical School, Chicago. New (2d) Edition. In one octavo volume. Pp. 717. With 453 engravings, of which $4 \bar{i}$ are in colors and 8 colored plates. Cloth, $\$ 5.00$, net. Leather, $\$ 5.00$, net. Philadelphia: Lea Brothers \& Co. 1899.

A Mandal of Modern Gastric Metuods, Chemical Physical and Therapeutrc. By A. Lockhart Gillespie, M.D., F.R.C.P.E., F.R.S.E. With a Chapter on the Mechanical Methods Used in Young Children. By John Thompson, M.D., F.R.C.P.E. 8vo. Cloth. Pp. 176. New York: William Wood \& Co. 1899. 